
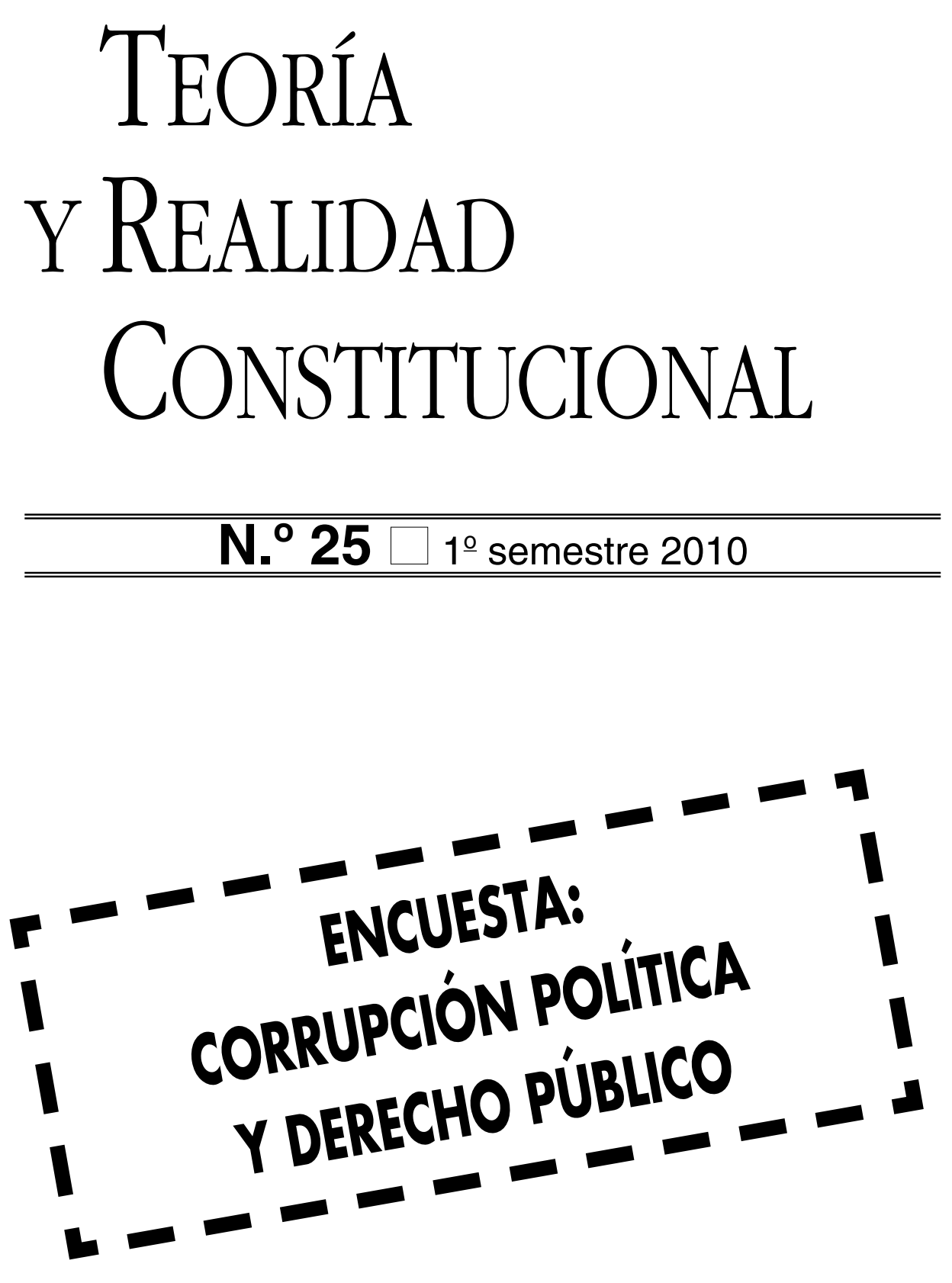


\title{
EL DELITO URBANÍSTICO: PROTECCIÓN PENAL DE PRINCIPIOS CONSTITUCIONALES BÁSICOS (Comentario a la sentencia del Tribunal Supremo de 27 de noviembre de 2009)
}

\author{
FRANCISCO DE COMINGES CÁCERES \\ Letrado del Tribunal Supremo
}
SUMARIO
I. Relevancia constitucional del proceso ur- banístico.
II. Medidas administrativas de prevención y reacción frente a la transgresión del ordenamiento urbanístico.
III. El "fracaso" del Derecho Administrativo.
IV. La conversión en delito del ilícito urba- nístico.
V. La sentencia del Tribunal Supremo de 27 de noviembre de 2009

\section{RELEVANCIA CONSTITUCIONAL DEL PROCESO URBANÍSTICO}

En la sentencia del Tribunal Supremo ${ }^{1}$ que analizamos se aborda una problemática de rabiosa actualidad en nuestros días: La reacción penal frente al proceso edificatorio y urbanizador ilegal realizado con la complicidad —acti-

1 Sala $2^{a}$. Recurso de casación 1539/2008, ponente: Excmo. Sr. García Pérez, aclarada por auto de 12 de enero de 2010. Confirma la condena de prisión e inhabilitación impuesta por la Audiencia Provincial de Mallorca al, en el momento de la comisión de los hechos, Alcalde de Andraitx, así como al entonces jefe de urbanismo de su Ayuntamiento (que luego sería nombrado Director General de Ordenación del Territorio del Gobierno Balear), al asesor jurídico y al inspector municipales, con motivo de la construcción ilegal de una vivienda en suelo no urbanizable de especial protección paisajística. 
va o pasiva - de los agentes de la propia Administración pública encargada de la salvaguarda de la legalidad urbanística. ${ }^{2}$

Se trata de una materia especialmente sensible porque afecta a principios y valores constitucionales relevantes, encarnados en la ordenación del territorio y en la planificación urbanística.

La "ordenación del territorio" ha sido definida en la Carta Europea homónima $^{3}$ como la "Expresión espacial de la política económica, social, cultural y ecológica de toda sociedad. Mediante ella se pretende favorecer el desarrollo equilibrado de las regiones, eliminar diferencias en el nivel de vida, mejorar su calidad, así como de las infraestructuras y equipamientos colectivos. Se dirige también a la utilización racional y equilibrada del territorio y a la gestión de los recursos naturales, atendiendo a las peculiaridades de cada comarca ${ }^{4}$.

En un nivel inferior, la "planificación urbanística" tiene como misión, en palabras del propio Tribunal Constitucional ${ }^{5}$, determinar el haz de aptitudes urbanísticas en cada terreno, haciendo compatible "el disfrute de las facultades urbanizadoras y edificatorias con la estructura y singularidades de cada ciudad.

Tanto la ordenación del territorio como la planificación urbanística, en su ejecución la dedicación efectiva del suelo a distintos usos-, obedecen a determinados principios constitucionales, vinculados a la propia esencia del Estado Social y de Derecho en el que nos hallamos.

Dichos principios, en lo que aquí importa, se positivizan en los artículos 33.2, 47, 45.2, 9.2 y 10 de la Constitución. En ellos, en primer lugar, se circunscribe el derecho a la propiedad privada al cumplimiento de "su función social (...) de acuerdo con las leyes" (art. 33.2) ${ }^{6}$. En segundo, se exige la regulación de "la utilización del suelo" conforme "al interés general para impedir la especulación" (art. 47). Y, en tercer lugar, se obliga a los poderes públicos a velar por el uso racional del suelo "con el fin de proteger y mejorar la calidad de la vida y defender y restaurar el medio ambiente, apoyándose en la indispensable solidaridad colectiva" (art. 45). Calidad de vida que lleva a determinados autores a vincular esta materia con la dignidad de la persona y el libre desarrollo de la personalidad en sociedad (arts. 10 y 9.2) ${ }^{7}$ e incluso a considerarla como un auténtico "derecho fundamental" ${ }^{8}$.

2 En la sentencia se analiza la comisión de delitos contra la ordenación del territorio (art. 319 del Código Penal) y de prevaricación urbanística (art. 320). No de cohecho (arts. 419 y ss), al no haberse denunciado, ni constatado, que ninguno de los encausados ofreciese o recibiese soborno o dádiva por su participación en los hechos.

323 de mayo de 1983.

4 Sentencias del Tribunal Constitucional 149/1998, de 2 de julio y 149/1991, de 4 de julio.

5 Sentencia 164/2001, de 11 de julio. También en la Sentencia del Tribunal Constitucional 61/1997, de 20 de marzo se define el urbanismo como la: “Disciplina jurídica del hecho social o colectivo de los asentamientos de población en el espacio físico".

6 Función social que no es un límite externo, sino que delimita intrínsecamente el contenido del derecho de propiedad.

7 CONDE-PUMPIDO, C., en (ALCARAZ RAMOS, M. Dir.,). "El Estado de Derecho frente a la corrupción urbanistica”. Ed. La Ley, 2007, pág. 20; PAREJO ALFONSO, L. “Ordenación del Terri- 
Se consagra así una concepción estatutaria del derecho de propiedad, en el sentido de que será la propia Ley —y en su aplicación el plan urbanísticola que defina el régimen de derechos y deberes de los propietarios, precisando y delimitando su contenido, estableciendo los requisitos necesarios para poder patrimonializar sus expectativas urbanas, proyectadas por la sociedad en el momento de llevar a cabo la ordenación?. Pero ello siempre en el marco de la "función social" de la propiedad, de la satisfacción del "interés general" y del objetivo teleológico último de mejora de la "calidad de vida" de los ciudadanos, mediante un desarrollo sostenible, configurándose a tal efecto el urbanismo como una función pública no susceptible de transacción ${ }^{10}$.

Desde esta perspectiva ha de insistirse en que la Constitución concibe el suelo (que es un recurso natural escaso y no renovable) no sólo como un bien socioeconómico, sino también, y sobre todo, como un bien ambiental ${ }^{11}$. La protección del medio ambiente como garantía de ese objetivo de "calidad de hábitat" al que nos referimos ha de entenderse como un "concepto estructural" (que abarca tanto la dimensión urbana, como la rural, en permanente interacción) y "transversal", al afectar a un cúmulo de situaciones y competencias administrativas, alcanzando una dimensión "erga omnes", objeto de intereses colectivos o difusos, que opera no sólo frente a los poderes públicos, sino también en las relaciones entre particulares ${ }^{12}$.

En la definición legal de ese "desarrollo sostenible" y de la "calidad de vida" a la que debe poder aspirar todo ciudadano ha adquirido en los últimos años singular relevancia la preocupación por el paisaje ${ }^{13}$, tanto rural, como ur-

torio y Medio Ambiente", en Revista de Derecho Urbanístico núm. 146, 1996,pág. 141; BERNAL DEL CASTILLO, J. “Delimitación del bien jurídico protegido en los delitos urbanísticos", en Revista de Derecho Penal y Criminología, 2 época, núm. 3, 1999, pág. 18.

8 PÉREZ LUÑO, A-E. "Artículo 45 - Medio Ambiente", en (ALZAGA VILLAAMIL, O. Dir.,) Comentarios a la Constitución Española de 1978", Cortes Generales-Editoriales de Derecho Reunidas. 1996. Tomo IV,pág. 258.

9 FERNÁNDEZ, T-R.. "Manual de Derecho Urbanístico”. El Consultor de los Ayuntamientos y Juzgados, $15^{a}$ edición,págs. 113 y ss. Concepción estatutaria del derecho de propiedad reconocida por nuestro Tribunal Constitucional, entre otras muchas, en sus sentencias 111/1983, 37/1987, 166/1986, 149/1991, 61/1997 y 164/2001. De ella se deriva una disociación entre el derecho a edificar y la titularidad dominical del suelo (FD 10 STC 61/1997, de 20 de marzo), como se reconoce ya, expresamente, en el artículo 7.2 del vigente Texto Refundido de la Ley de Suelo, aprobado por Real Decreto Legislativo 2/2008, de 20 de junio (TRLS-2008). El "ius aedificandi", o facultad para transformar un terreno en urbano y edificar en él, no forma parte del derecho de la propiedad urbana al que se refieren los arts. 33 y 53.1 CE (Sentencia del Tribunal Supremo de 16 de diciembre de 1985 - RJ 655-).

10 Art. 3.1 del Texto Refundido de la Ley de Suelo, aprobado por Real Decreto Legislativo 2/2008, de 20 de junio (TRLS-2008).

11 VAQUER CABALLERÍA, M. «Estudio preliminar: Constitución, Ley de suelo y ordenamiento territorial y urbanístico", en ( PAREJO ALFONSO, L. Dir.), "Comentarios a la Ley de Suelo". Iustel, 2007,pág. 22.

12 Sentencia del Tribunal Constitucional 102/1995, de 26 de junio.

13 OCHOA GÓMEZ, M.P. "La juridificación del paisaje,o de cómo convertir un criterio esencialmente estético en un bien jurídico objetivable». Revista Urbanística Práctica La Ley, núm. 89, 2010, págs. 61 y ss. 
bano, tratándose de un "elemento esencial para el bienestar individual y social, cuya protección, gestión y planeamiento comporta derechos y obligaciones para todos ${ }^{14}$.

Y así se dispone expresamente en la legislación urbanística estatal vigente, que las "edificaciones habrán de adaptarse, en lo básico, al ambiente en que estuvieran situadas, y a tal efecto, en los lugares de paisaje abierto y natural, sea rural o marítimo, o en las perspectivas que ofrezcan los conjuntos urbanos de características histórico-artísticas, típicos o tradicionales, y en las inmediaciones de las carreteras y caminos de trayecto pintoresco, no se permitirá que la situación, masa, altura de los edificios, muros y cierres o la instalación de otros elementos, limite el campo visual para contemplar las bellezas naturales, rompa la armonía del paisaje o desfigure la perspectiva propia del mismo" ${ }^{15}$.

También diversas comunidades autónomas le han dedicado una normativa propia y específica, en la que, entre otros aspectos, se regula el paisaje como un parámetro limitativo del derecho a edificar ${ }^{16}$.

Todas estas vinculaciones no contradicen la obligación del legislador de respetar el "contenido esencial", nuclear e indisponible del derecho de propiedad (art. $53.1 \mathrm{CE})^{17}$, porque, conforme a la doctrina y la jurisprudencia con-

14 Convenio europeo del paisaje, aprobado en Florencia el 20 de octubre de 2000 a propuesta del Consejo de Europa. Ratificado el 26 de nobiembre de 2007 por España, entró en vigor el 1 de marzo de 2008. Se pretendió en él, de una parte, otorgarle un reconocimiento jurídico. Y, de otra, promover "políticas de paisaje".

15 Art. 10.2 TRLS-2008, norma de carácter básico en la que prácticamente se reproduce lo ya dispuesto al respecto en la legislación urbanística estatal anterior. En aplicación de la misma, el Tribunal Supremo ( $S^{a} 3^{a}$ ) en su sentencia de 18 de abril de 2000 (casación 8680/1994) confirmó la anulación de una licencia de obras otorgada para construir más de 100 viviendas tras apreciar su "inadaptación al ambiente".

16 Sirva como ejemplo la Ley gallega $7 / 2008$, de 7 de julio, de protección del paisaje, en cuya exposición de motivos se reconoce que: "se trata de un recurso patrimonial incuestionable que participa del interés general en los aspectos ecológicos, culturales, económicos y sociales. El paisaje proporciona el marco idóneo en su concepción holística para abordar la comprensión y el análisis del territorio, de las políticas de desarrollo sostenible necesarias para su puesta en valor y de los procesos ecológicos que en él tienen lugar. Porque el paisaje es un elemento fundamental de la calidad de vida de las personas y por ello también debe ser el fiel reflejo de un territorio y de un medio ambiente de calidad, de una sociedad moderna y consciente de la importancia de su patrimonio natural y cultural, de una sociedad en relación armónica con el medio donde primen el uso racional del territorio, el aprovechamiento sostenible de sus recursos, un desarrollo urbanistico respetuoso y el reconocimiento de las funciones principales que juegan los ecosistemas naturales.Una de las nuevas disciplinas más interesantes es la ecología del paisaje, constituyendo boy una poderosa herramienta para la ordenación del territorio con criterios de sostenibilidad ecológica. Resulta además de especial interés para diseñar áreas protegidas, para comprender la evolución y la perturbación que sufren los ecosistemas naturales y la diversidad biológica, y especialmente para comprender y analizar las causas de la artificialización y degradación de los paisajes.

17 En este sentido, el Tribunal Constitucional ha señalado en su Sentencia 37/1987, de 26 de marzo que: "la determinación del contenido esencial de cualquier tipo de derecho subjetivo viene marcada en cada caso por el elenco de facultades o posibilidades de actuación necesarias para que el derecho sea recognoscible como perteneciente al tipo descrito y sin las cuales deja de per- 
solidada sobre la materia éste sólo alcanza a la explotación rústica de los terrenos - con las limitaciones establecidas para ello en la normativa sectorial aplicable- - No incluye, en principio, las "expectativas urbanísticas" o plusvalías originadas por el crecimiento de la ciudad.

La recientemente derogada Ley 6/1998, de 13 de abril, de Régimen de Suelo y Valoraciones pretendió alterar este axioma tradicional de nuestro Derecho urbanístico al atribuirle - frente a la legislación anterior - a la clase de suelo urbanizable una naturaleza residual, extensible a todo tipo de terrenos sobre los que no concurriesen circunstancias especiales que obligasen a otorgarles otra clasificación. Podría considerarse que como consecuencia de ello el "contenido normal del derecho de propiedad" incorporaba, bajo la vigencia de dicha Ley, la expectativa de un aprovechamiento urbanístico. Las consecuencias de ese "giro copernicano" fueron nefastas, constituyendo una de las causas principales de la "burbuja inmobiliaria" que se produjo en la primera década de este siglo, al provocar una urbanización del suelo desmedida y con fines puramente especulativos en buena parte del territorio español, incrementándose - paradójicamente y frente a la intención expresa del legislador- el precio del suelo y los supuestos de corrupción urbanística ${ }^{18}$.

La posterior Ley estatal 8/2007, de 28 de mayo, de suelo y el Texto Refundido al que dio lugar, aprobado por Real Decreto Legislativo 2/2008, de 20 de junio, actualmente en vigor, recuperaron la concepción tradicional anterior a la Ley 6/1998 sobre el contenido "normal" del derecho de propiedad. Se le restituyó así su naturaleza residual al "suelo rural", es decir a los terrenos no urbanizados (art. 12.2), sobre los que sus propietarios no ostentarán más derecho que "el uso agrícola, ganadero, forestal, cinegético o cualquier otro vinculado a la utilización racional de los recursos naturales" (art. 13.1).

En la exposición de motivos de la Ley se insiste también en que el urbanismo debe responder a los requerimientos de un desarrollo sostenible, apostando por un modelo de ciudad compacta, frente a los inconvenientes que genera la urbanización dispersa o desordenada: impacto ambiental, segregación social e ineficiencia económica por los elevados costes energéticos, de construcción y de mantenimiento de infraestructuras y de prestación de los servicios públicos.

Con este punto de partida, en el supuesto examinado en la sentencia que analizamos se plantea precisamente un conflicto entre los referidos valores constitucionales (utilización racional del suelo, primacía del interés público sobre el privado, protección del medio ambiente y de la calidad de vida como interés colectivo) materializados en el planeamiento, el interés de un propietario de suelo en edificar en él una vivienda (en contra del plan, que lo clasificó como no urbanizable por razones paisajísticas), y el deber de las auto-

tenecer a ese tipo y tiene que pasar a quedar comprendido en otro, desnaturalizándose. Todo ello referido al momento bistórico de que en cada caso se trata y a las condiciones inherentes en las sociedades democráticas, cuando se trate de derechos constitucionales" (F 2).

18 Según datos del Banco de España, entre 1998 y 2005 los precios de la vivienda se incrementaron un $150 \%$ y el del suelo urbano se elevó un 500\%. 
ridades y funcionarios municipales de velar por el cumplimiento de la legalidad urbanística.

\section{MEDIDAS ADMINISTRATIVAS DE PREVENCIÓN Y REACCIÓN FRENTE A LA TRANSGRESIÓN DEL ORDENAMIENTO URBANÍSTICO}

La vulneración del ordenamiento urbanístico mediante la construcción de edificaciones ilegales en parajes protegidos -como es el caso- supone una agresión directa a los valores constitucionales descritos en el epígrafe anterior. Un ataque de especial gravedad por cuanto genera una situación de hecho que con el tiempo se consolida y se hace prácticamente irreversible. Sobre todo cuando se trata de viviendas enajenadas a terceros adquirentes, o cuando han sido autorizadas mediante licencias ilegales. Supuestos en los que la restauración de la legalidad urbanística infringida provoca un grave problema social (requiere desalojar a las familias que han adquirido las viviendas con un gran esfuerzo económico) y patrimonial para la propia Hacienda municipal (que habría de asumir importantes indemnizaciones).

Con el fin de evitar o resolver estas situaciones, se establecen en nuestro ordenamiento jurídico varias medidas preventivas y coercitivas, de naturaleza administrativa ${ }^{19}$, entre las que merecen reseñarse las siguientes:

\section{a) Medidas PReVentivas}

La mayoría de ellas se dirigen a garantizar la transparencia del proceso urbanístico, mediante técnicas de información y participación pública efectivas ${ }^{20}$. Así, por ejemplo, en la legislación vigente se exige la exposición pública de "todos los instrumentos de ordenación territorial y de ordenación y ejecución urbanísticas", incluidos los "Convenios urbanísticos", con carácter previo a su aprobación definitiva ${ }^{21}$. También la obligación de publicar, por medios telemáticos, el contenido actualizado de los instrumentos de ordenación territorial y urbanística en vigor y de las incidencias que les afecten ${ }^{22}$. Y, por supuesto, se reconoce el derecho de todo ciudadano a solicitar información por escrito sobre el régimen y condiciones urbanísticas aplicable a cualquier finca ${ }^{23}$.

19 RASTROLLO SUÁREZ, J.J. “Corrupción urbanística: una perspectiva actual. Mecanismos administrativos de prevención”. Revista Urbanística Práctica La Ley, núm. 88, 2009, págs. 42 y ss.

20 Lo que en último término obedece al mandato contenido en el artículo 105 de la Constitución. Se explicitan en los artículos 4 y 11 TRLS-2008, en los que se detallan los derechos de los ciudadanos de participación y acceso a la información en los asuntos urbanísticos.

21 Art. 11 TRLS-2008.

22 Aptdo. 2 del art. 70.ter de la Ley 7/1985, de 2 de abril, de Bases del Régimen Local (LBRL), introducido por Ley 8/2007, de 28 de mayo, de Suelo.

23 Art. 4.d) TRLS-2008. 
Otras tienen por objeto la prevención y control de un posible enriquecimiento ilícito por las autoridades públicas y promotores intervinientes en el proceso urbanístico, como la prescripción que obliga a incluir en las modificaciones puntuales del planeamiento "la identidad de todos los propietarios o titulares de otros derechos reales sobre las fincas afectadas durante los cinco años anteriores a su iniciación ${ }^{24}$. O la que le exige a los representantes y altos cargos locales formular una declaración jurada sobre sus bienes, causas de posible incompatibilidad y "cualquier actividad que les proporcione o pueda proporcionar ingresos económicos", prohibiéndoles a su vez el desempeño de determinadas actividades privadas durante los dos años posteriores al cese de su mandato ${ }^{25}$.

Se establecen igualmente mecanismos de fiscalización y control preventivo de la actividad urbanística de las Administraciones municipales por los entes públicos territoriales superiores ${ }^{26}$, como por ejemplo mediante la emisión por estos últimos de informe preceptivo y vinculante en determinados procedimientos $^{27}$, o mediante la obligación de los Ayuntamientos de remitirles periódicamente información sobre su actividad ${ }^{28}$.

\section{B) MedidAs De REACCIÓN O COERCITIVAS}

En la normativa reguladora de la disciplina urbanística se insiste en que en ningún caso podrá la Administración competente dejar de adoptar las medidas necesarias para el restablecimiento de la legalidad infringida. Medidas que en síntesis se articulan mediante tres procedimientos administrativos distintos: Uno, denominado de "protección de la legalidad", dirigido a la restauración física de los terrenos a su situación anterior a la de comisión de la infracción ${ }^{29}$. Otro, sancionador, que concluirá con la imposición de una multa a los culpables ${ }^{30}$. Y, por último, si las obras se amparasen en el otorgamiento de una licencia ilegal, se prevé un tercer procedimiento de revisión de oficio de la misma, con simultánea paralización de aquéllas. Ello sin perjuicio de la potestad disciplinaria de la Administración sobre su propio

24 Aptdo. 3 del citado art. 70.ter LBRL.

25 Art. 75 y disposición adicional décimoquinta LBRL, también introducida por la citada Ley $8 / 2007$

26 El Tribunal Constitucional admitió su compatibilidad con el principio de autonomía local siempre e cuando los controles tengan carácter concreto y específico y se refieran a supuestos en los que el ejercicio de las competencias municipales incida sobre intereses generales de la comunidad autónoma o del Estado (SSTC 4/1981, 117/1984, 187/1988 o 192/2000).

27 Ad. ex. art. 15 TRLS-2008 (informes de sostenibilidad ambiental, suficiencia de recursos hídricos, sobre carreteras y demás infraestructuras de titularidad autonómica o estatal, etc).

28 Art. 196.3 Real Decreto 2568/1986, de 28 de noviembre, aprobatorio del Reglamento de Organización y Funcionamiento de las Corporaciones Locales. Art. 56.2 LBRL.

29 En ejercicio de una potestad de autotutela administrativa, no sancionadora.

30 Entre los que, en ciertos supuestos, se incluyen los empleados públicos que informasen favorablemente la autorización ilegal de que se trate. 
personal frente a las faltas que cometan en el ejercicio de sus funciones públicas.

Como con carácter general se le atribuyen a los ayuntamientos estas potestades coercitivas urbanísticas, existe la posibilidad de que las Administraciones autonómica o estatal se subroguen en su ejercicio cuando el ente local incurra en una grave dejación de funciones ${ }^{31}$. También puede la Comunidad Autónoma en supuestos especiales suspender el planeamiento urbanístico en cuestión, exigiendo su revisión y adaptación a los parámetros de sostenibilidad establecidos en la legislación vigente ${ }^{32}$.

Y, en fin, en supuestos extremos, dicho control puede llegar incluso a la disolución del propio Ayuntamiento, como sucedió en el caso de Marbella, cuya Corporación Municipal fue disuelta mediante Real Decreto 421/2006, de 7 de abril con motivo, entre otros extremos, de su incumplimiento masivo e indiscriminado de la legalidad urbanística aplicable.

En otro nivel, los órganos jurisdiccionales contencioso-administrativos disponen de un variado elenco de medios para asegurar el cumplimiento de la legalidad urbanística frente a la inactividad o a la actuación irregular de la Administración ${ }^{33}$. Medidas reforzadas por la circunstancia de que en esta materia se reconoce la "acción pública", de manera que cualquier ciudadano goza de legitimación para promover el proceso sin necesidad de acreditar ningún interés especial más que el de la mera y abstracta defensa de la legalidad ${ }^{34}$.

En este campo resulta fundamental la adopción de medidas cautelares para asegurar el posterior cumplimiento de una posible sentencia que condene al derribo de las obras ilegales ejecutadas al amparo o no de licencia. Como se ha dicho, la experiencia demuestra que la consolidación física de la

31 Art. 60 Ley 7/1985, de 2 de abril, de Bases de Régimen Local. El Tribunal Constitucional consideró en su sentencia 159/2001, de 5 de julio (FD 6 y ss.), que la sustitución o subrogación debe ser en todo caso "meramente funcional y limitada a la actuación de que se trate". Ha de motivarse en un "incumplimiento cualificado" que afecte a competencias estatales o autonómicas tras desatender los requerimientos previos que necesariamente se le deben comunicar.

32 Así por ejemplo, el Consello de la Xunta de Galicia, tras constatar el grave déficit de dotaciones públicas y la elevada edificabilidad de que adolecían determinados instrumentos de planeamiento general aprobados mucho tiempo atrás, acordó la suspensión de los de los municipios de Teo (Decreto 115/2001, de 25 de mayo), Oroso (Decreto 162/2002, de 10 de mayo), Ponteareas (Decreto 207/2002, de 20 de junio) y O Grove (Decreto 208/2002, de 20 de junio, DOG 119, do 21/06/2002), estableciendo una ordenación provisional, pendiente de la aprobación de un nuevo plan general adaptado a las exigencias de dotaciones y equipamientos, y límites de edificabilidad de la nueva legislación urbanística.

Véase SÁNCHEZ GOYANES, E., "La suspensión autonómica del planeamiento urbanístico municipal: su reconducción hacia límites aceptables constitucionalmente». Revista de Urbanismo y Edificación núm. 6. Ed. Aranzadi, 2002.

33 Ley 29/1998, de 13 de julio, reguladora de la Jurisdicción Contencioso-Administrativa.

34 Arts. 4.f) y 48 TRLS-2008. Véase también la Ley 27/2006, de 18 de julio, por la que se regulan los derechos de acceso a la información, de participación pública y de acceso a la justicia en materia de medio ambiente, que incorpora a nuestro derecho interno las Directivas 2003/4/CE y 2003/35/CE, así como los principios del Convenio de Aarhus ratificado por España en diciembre de 2004 . 
infracción mediante la realización efectiva de la edificación ilegal y su enajenación a terceros adquirentes dificulta sobremanera, o impide incluso la ejecución de la consiguiente orden de derribo. Es por ello esencial suspender cautelarmente y desde el primer momento dichas obras, tomando en consideración la entidad del daño paisajístico y ambiental que es susceptible de causar, así como los indicios de ilegalidad que le pudieran afectar ${ }^{35}$.

En este punto, aunque tradicionalmente la Jurisdicción contencioso-administrativa se ha mostrado en general reacia a suspender al inicio del proceso, como medida cautelar, los planes o licencias impugnados, o -en su reverso- para no suspender las órdenes administrativas de demolición recurridas, lo cierto es que en la actualidad se está produciendo un cambio jurisprudencial en el sentido opuesto. Y así son ya numerosas las sentencias de nuestro Tribunal Supremo en las que se considera procedente la paralización cautelar de los planes o autorizaciones impugnados, al primar, en la ponderación de los intereses en conflicto, el público representado en la protección del medio ambiente y en la defensa de un desarrollo sostenible, sobre el económico de una nueva urbanización residencial o industrial de iniciativa privada $^{36}$. También las que, en la vertiente contraria, están denegando la suspensión cautelar de órdenes administrativas de derribo de edificaciones erigidas sin licencia sobre suelo no urbanizable protegido ${ }^{37}$.

35 SORIANO GARCIA, E. “Urbanismo y corrupción: medidas cautelares, única solución”. Revista El Notario del Siglo XXI, núm. 29, febrero 2010, págs. 32 y ss.

36 Sentencias del Tribunal Supremo, $S^{a} 3^{a}$, Secc. $5^{a}$, de 29 de enero de 2010 (casación 5877/2008), 25 de febrero de 2009 (casación 872/2008), 30 de marzo de 2009 (casación 790/2008), 18 de diciembre de 2008 (casación 3743/2007), 23 de diciembre de 2008 (casación 3854/2007), 3 de febrero de 2009 (casación 5125/2007) y 29 de diciembre de 2008 (casación 2161/2007). En la última de las citadas se confirma la suspensión cautelar del plan urbanístico recurrido, atendiendo a que: "No cabe duda que existe una linea jurisprudencial reticente a la suspensión de los instrumentos de ordenación general, que requieren, a su vez, otros instrumentos de desarrollo y, para su efectiva y última ejecución, actos concretos de aprobación de proyectos o la concesión de licencias de obras, pero también existe una corriente jurisprudencial paralela que, en evitación de múltiples recursos o impugnaciones en vía administrativa y sede jurisdiccional, viene accediendo a suspender la ejecutividad de los instrumentos de planeamiento cuando hay riesgo, como en este caso, de que, de no suspenderse la aplicación o ejecución del ordenamiento urbanistico aprobado, pierda su legítima finalidad el recurso contencioso-administrativo". En ese concreto caso, "de no suspenderse su ejecutividad, cuando se dictase una sentencia estimatoria, se habria llevado a cabo la ejecución de un planeamiento urbanistico radicalmente nulo, lo que contradice el más elemental principio de que cualquier actuación urbanistica debe ajustarse a la legalidad, que es por lo que, en cualquier caso, debe velar la jurisdicción al decidir acerca de la suspensión o no de decisiones en esta materia, en la que los sucesivos instrumentos de ordenación concatenados, seguidos de actos de ejecución, suelen hacer irreversibles las situaciones, que, como el propio Ayuntamiento admite al articular su recurso de casación, sólo tienen solución a través de revisiones del planeamiento urbanistico o de las consiguientes demoliciones, de compleja y muy costosa realización ésta, y conducentes, de ordinario, aquéllas a declaraciones de imposibilidad legal de ejecutar las sentencia, que realmente encubren auténticos incumplimientos de sentencias firmes".

37 Sentencias del Tribunal Supremo ( $\mathrm{S}^{\mathrm{a}} 3^{\mathrm{a}}$, Secc. $5^{\mathrm{a}}$ ) de 14 de mayo de 2009 (casación 579/2008) y 13 de julio de 2009 (casación 983/2008). 


\section{EL "FRACASO» DEL DERECHO ADMINISTRATIVO}

Aunque en nuestro ordenamiento administrativo se establecen medidas preventivas y coercitivas idóneas para mitigar y corregir las irregularidades urbanísticas, lo cierto es que, en la práctica, se percibe la sensación de hallarnos en España en una situación de indisciplina urbanística generalizada, en la que se cometen agresiones constantes y muy graves al paisaje, a la "calidad de hábitat" en sí, mediante la urbanización masiva, insostenible y descontrolada de amplias superficies de suelo en lugares medioambientalmente sensibles, careciendo la Administración, y la Justicia contencioso-administrativa de una capacidad de respuesta o reacción eficaz.

El Parlamento Europeo se hizo eco del problema en su conocida resolución de 26 de marzo de 2009 "sobre el impacto de la urbanización extensiva en España en los derechos individuales de los ciudadanos europeos, el medio ambiente y la aplicación del Derecho comunitario" "38. En ella denunció que "todas las Administraciones, central, autonómicas y locales han sido responsables de haber puesto en marcha un modelo de desarrollo insostenible, que ha tenido gravísimas consecuencias, por supuesto medioambientales y, además, sociales y económicas". También que los procesos judiciales incoados frente a las prácticas urbanísticas irregulares padecen "una lentitud desmedida", y que "las sentencias dictadas en muchos de estos casos no pueden ejecutarse de forma que compensen a las víctimas de tales abusos, lo que ha reforzado la impresión, compartida por muchos ciudadanos de la UE de nacionalidad no española, acerca de la falta de actuación y parcialidad de la justicia española". E insistió así mismo en que: "la falta de claridad, precisión y certidumbre respecto a los derechos de propiedad individual contemplados en la legislación en vigor y la falta de aplicación adecuada y sistemática de la legislación en materia de medio ambiente son la primera causa de muchos problemas relacionados con la urbanización. Esto, combinado con cierta laxitud en los procesos judiciales, no sólo ha complicado el problema, sino que también ha generado una forma endémica de corrupción.

En igual sentido, la organización no gubernamental Transparencia Internacional en su informe del año 2006 puso de manifiesto que en España: "el ámbito donde la corrupción es más elevada es el del nivel local de Gobierno", por causa de desarrollos urbanísticos "sobre todo en la costa (...) o en las inmediaciones de las grandes ciudades". El origen de este fenómeno, según dicha asociación, radica en las recalificaciones de suelo, lo que ha provocado que España sea el país de la OCDE «donde el precio de la vivienda ha subido más en los últimos años".

Al margen de las exageraciones en que pudieren haber incurrido los citados informes, es evidente que, en efecto, no se están cumpliendo adecuadamente los objetivos previstos en la normativa reguladora de la disciplina urba-

38 Dio aprobación al Informe Auken ${ }^{\natural}$ (elaborado por la eurodiputada verde danesa Magrete Auken, tras 5 años de estudios con la colaboración de plataformas y ciudadanos españoles). 
nística. Como regla general los ayuntamientos no proceden nunca de oficio a derribar construcciones ilegales terminadas y habitadas. Es preciso que un denunciante, tras un largo y costoso periplo en la vía administrativa y contencioso-administrativa, consiga una sentencia firme que les conmine a ello. Y aún así el incidente ejecutorio de la sentencia resultará también complejo y muy prolongado en el tiempo, pudiendo culminar incluso con la declaración de su inejecución "por imposibilidad legal" porque entre medias se modificó el plan con el objeto -encubierto o no- de legalizar la edificación ${ }^{39}$.

Se estima que a día de hoy en España existen más de 100.000 viviendas ilegales (buena parte de ellas en lugares próximos a la costa, o de elevado valor medioambiental y ecológico ${ }^{40}$, de las cuales más de 4.000 se construyeron al amparo de licencia de obras anulada por sentencia firme, pendiente de ejecución a día de hoy ${ }^{41}$.

\section{LA CONVERSIÓN EN DELITO DEL ILÍCITO URBANÍSTICO}

El derecho penal responde a los principios de subsidiariedad y fragmentariedad. Es decir, debe intervenir exclusivamente en aquellos supuestos en los que represente el único remedio eficaz para salvaguardar el bien jurídico objeto de protección, y sólo ante los ataques más graves e intolerables, atendiendo al criterio de "intervención mínima” y “último ratio" "2 La labor de tipificación de los delitos le corresponde al legislador ordinario en el marco de la defensa de los valores constitucionales, atendiendo a la realidad social del momento.

Dicho esto, y en el contexto descrito en los epígrafes anteriores, en el vigente Código Penal de 1995 se tipificaron, por primera vez, los "delitos contra la ordenación del territorio "43, otorgándosele así relevancia penal a hechos que hasta entonces no constituían más que meros ilícitos administrativos.

39 GEIS I CARRERAS, G. “La ejecución de las sentencias urbanísticas”. Atelier, 2009,págs. 126 y ss. En este reciente titular del diario La Voz de Galicia de 12 de febrero de 2010 se refleja perfectamente el mensaje percibido por la opinión pública sobre la cuestión: "Lentitud judicial, dejación política y falta de fondos frenan los derribos. El reguero de recursos, la inseguridad jurídica que rodea al urbanismo y el intento de los ayuntamientos de evitar indemnizaciones, ingredientes añadidos".

40 LOZANO CUTANDA, B. «Urbanismo y corrupción: algunas reflexiones desde el Derecho administrativo". Revista de Administración Pública, núm. 172, 2007,págs. 339 y ss.

Así lo reconoció el fiscal coordinador de urbanismo y medio ambiente D. Antonio Vercher en sendas entrevistas publicadas en el diario El País en los días respectivos 1 de marzo de 2005 y 30 de octubre de 2006.

41 Los casos de los municipios de Marbella (Andalucía), Piélagos (Cantabria) y Ponteareas (Galicia) son algunos de los más llamativos, atendiendo al número de viviendas afectadas por las licencias anuladas.

42 NAVARRO CARDOSO, F. “Infracción administrativa y delito: límites a la intervención del Derecho penal». Cólex, Madrid, 2001,pág. 91.

43 En realidad los delitos tipificados bajo dicha denominación se insertan en la materia propiamente "urbanística", más que en la de la "ordenación del territorio" stricto sensu, que definimos al comienzo de este comentario. 
Cierta parte de la doctrina consideró que se trataba de un delito "formal" dirigido a castigar la desobediencia de lo dispuesto en la normativa urbanística, que se constituía así en el bien jurídico objeto de protección ${ }^{44}$. Le achacó a esta nueva regulación generar inseguridad jurídica, al remitirse, como ley en blanco, a una compleja y profusa legislación, la urbanística, difícil de interpretar por los órganos jurisdiccionales penales (no especializados en el Derecho administrativo), que además es diferente en cada una de las Comunidades Autónomas, a las que les corresponde la titularidad exclusiva sobre su regulación ${ }^{45}$. También los conflictos que podrían generarse en relación al principio "ne bis in idem" ${ }^{46}$ al proyectarse sobre conductas ya tipificadas como infracción administrativa en la legislación urbanística ${ }^{47}$. Y, en lo referente a los delitos de prevaricación urbanística, insiste en la innecesaridad de crear nuevos tipos penales especiales frente a conductas que podrían castigarse acudiendo a las reglas generales de coautoría y participación en el propio delito de ordenación del territorio, o a las del delito genérico de prevaricación administrativa, tachándolos de "Derecho penal simbólico" deslegitimado y pernicioso para la salvaguarda del bien jurídico que se pretende proteger, resultando además proclives a ser utilizados como instrumento de presión o de lucha política entre los distintos partidos ${ }^{48}$.

Otro sector le atribuyó sin embargo un carácter material, considerando que el bien jurídico protegido en este tipo de delitos es, con carácter primordial, el derecho a la "calidad de vida" de los ciudadanos, en el que confluyen los valores constitucionales regulados en los artículos 47 (utilización del suelo de acuerdo con el interés general) y 45 (derecho a un medio ambiente adecuado) de nuestra Carta Magna ${ }^{49}$. También el "urbanismo" en sí, visto desde una concepción antropocéntrica, "por cuanto en él se vienen a englobar circunstancias, condiciones y factores referentes al hombre que le vinculan con el medio en que

44 MUÑOZ CONDE, F. "Derecho penal. Parte especial”, 14ª edic., 2002, pág. 486.

Narváez Rodríguez, A: "Los delitos sobre ordenación del territorio: la responsabilidad penal de la Administración urbanístican. Actualidad penal, núm. 16, 1997.

45 ÚBEDA TARAJANO, F.E. "La responsabilidad por el otorgamiento de licencias ilegales". Iustel, 2006, págs.103 y ss. SÁENZ DE PIPAÓN, J. "La ciudad, objeto de protección penal. Acerca del llamado delito urbanistico". Ed. La Ley, 2009, págs. 163 y ss. MATALLANES RODRÍGUEZ, N. "Algunas notas sobre la dificultad de demarcar un espacio de tutela penal para la ordenación del territorio". Revista Penal,núm. 8, 2001, pág. 64.

46 Derivado del principio de legalidad reconocido en el artículo 25 de la Constitución (S TC 2/1981), de acuerdo con el cual: "nadie puede ser sancionado dos veces por el mismo hecho y con el mismo fundamento". Garantía que, en principio y conforme al criterio establecido por el Tribunal Constitucional en su sentencia 177/1999, de 11 de octubre (matizado en la posterior S TC $2 / 2003$, de 16 de enero), prevalece sobre el principio de preferencia de la jurisdicción penal respecto de la potestad administrativa sancionadora.

47 GIMENO SENDRA, V. "Estudio preliminar" en "Cuestiones prejudiciales devolutivas y non bis in idem en el proceso penal, en BALLBÉ MALLOL/PADRÉS REIG: La prejudicialidad administrativa en el proceso penal. Ed. Thomsom-Civitas. 2004, págs. 30, 42 y ss. BOLDOVA PASAMAR, M.A., "Los delitos urbanísticos". Ed. Atelier. 2007, págs. 55 y ss.

48 ÚBEDA TARAJANO, F.E. "La responsabilidad ..... op. cit., págs. 267 y ss.

49 SÁNCHEZ DOMINGO, M.B. "Delitos urbanísticos". Ed. Lex Nova, págs. 33 y ss. 
se desenvuelve, haciendo de la tierra y del suelo su eje operativo "50. Y, en lo que se refiere a la prevaricación urbanística, la defensa de la Administración pública, del deber de los servidores públicos de actuar con probidad y lealtad hacia ella y del principio de igualdad en la aplicación de la Ley.

La Sala de lo Penal del Tribunal Supremo se ha decantado por esta tesis ${ }^{51}$, entendiendo que los delitos urbanísticos responden al valor material de la ordenación del territorio, en su sentido constitucional de "utilización racional del suelo orientada a los intereses generales" (arts. 45 y 47 CE.), es decir el tratamiento del suelo como recurso natural limitado y la adecuación de su uso al interés general.

Reconoce así que constituye un bien jurídico comunitario de los denominados "intereses difusos", pues no pertenece a un titular concreto, sino que su lesión perjudica - en mayor o menor medida - a toda una colectividad. Su protección se inscribe en el fenómeno general de incorporación a la protección penal de intereses supraindividuales o colectivos, obedeciendo a la exigencia de intervención de los Poderes Públicos para tutelar estos intereses sociales, en congruencia con los principios rectores del Estado Social y Democrático de Derecho que consagra nuestra Constitución.

Y en esa línea nuestro Máximo Tribunal ha concluido asímismo que "la necesidad de la normativa penal no parece cuestionable. De una parte, la progresiva degradación del medio ambiente producida, entre otras razones, por una incumplida ordenación del territorio; y además, los postulados derivados de nuestra progresiva integración europea nos obliga a asumir la recomendación del Consejo de Europa, Comité Ministros de 25.1.84, que define los objetivos fundamentales de la ordenación del territorio: el desarrollo socio-económico equilibrado de las regiones; la mejoría de su calidad de vida, la gestión responsable de los recursos naturales y la protección del medio ambiente, y la utilización racional del territorio. Consecuentemente una cosa es que la realización de estos delitos presupongan que sólo se castiguen las conductas más graves entre la disciplina urbanística contenidas en la normativa de ordenación del territorio y otra completamente distinta es que la interpretación de los arts. 319 y 320 [del Código Penal] haya de bacerse sistemáticamente bajo la suposición prioritaria del principio de intervención mínima, constatadas que sean los elementos constitutivos del tipo penal, ${ }^{52}$.

La necesidad de protección penal del medio ambiente se ha reforzado también desde la Unión Europea, en la que se está promoviendo la creación de un "Derecho penal comunitario" sobre esta concreta materia ${ }^{53}$.

50 BLANCO LOZANO, C. "La protección penal del suelo no urbanizable». Diario La Ley, 5724 , 21/02/2003; y CARMONA SALGADO, C. en Cobo del Rosal (dir) "Curso de derecho penal español, Parte especial", T. II, 1997, pág. 19.

51 Sentencia de 28 de marzo de 2006 — casación 2067/2004-

52 Fundamento de Derecho noveno de la referida sentencia de 28 de marzo de 2006.

53 CONDE-PUMPIDO, C. Op. cit.pág. 21, en alusión a la sentencia del Tribunal de Justicia de Luxemburgo de 13 de septiembre de 2005, referida a la Decisión Marco de 27 de enero de 2003 , relativa a la protección del medio ambiente a través del Derecho penal. 
Nuestra jurisprudencia penal ha delimitado los presupuestos necesarios para poder apreciar la comisión de un delito contra la ordenación del territorio (art. $319 \mathrm{CP}$ ), exigiendo la concurrencia cumulativa de los siguientes requisitos $^{54}$ :

a) El sujeto activo debe reunir la condición de promotor, constructor o técnico director de la obra, entendiéndose por promotor quien impulse, programe o financie la construcción, para sí o para su posterior enajenación; b) Ha de realizarse una construcción; c) Debe carecer de la pertinente autorización, o ser disconforme con la otorgada; d) Esa construcción no autorizada ha de tener lugar "en suelos destinados a viales, zonas verdes, bienes de dominio público o lugares que tengan, legal o administrativamente reconocido su valor paisajístico, ecológico, artístico, bistórico o cultural, o por los mismos motivos hayan sido considerados de especial protección"; e) Ha de concurrir dolo en cualquiera de sus clases: directo de primer grado o intención, o dolo directo de segundo grado o de consecuencias necesarias, o dolo eventual.

Y en lo que se refiere al delito de prevaricación urbanística (art. 320 CP), ha de producirse ${ }^{55}$ :

a) Una resolución dictada por autoridad o funcionario en asunto administrativo; b) que sea contraria al Derecho; c) que esa contradicción con el derecho o ilegalidad, que puede manifestarse en la falta absoluta de competencia, en la omisión de trámites esenciales del procedimiento o en el propio contenido sustancial de la resolución, sea de tal entidad que no pueda ser explicada con una argumentación técnico-jurídica mínimamente razonable; d) que ocasione un resultado materialmente injusto; e) que la resolución sea dictada con la finalidad de hacer efectiva la voluntad particular de la autoridad o funcionario, y con el conocimiento de actuar en contra del derecho.

Este último requisito es, por lo común, el de más difícil acreditación en el proceso penal. Es necesario demostrar en él que el autor del delito actúa a sabiendas de la injusticia o arbitrariedad de sus actos, de que tiene plena conciencia de que resuelve al margen del ordenamiento jurídico y de que ocasiona un resultado materialmente injusto, actúa de tal modo porque quiere este resultado y antepone el contenido de su voluntad a cualquier otro razonamiento o consideración.

En la práctica los órganos jurisdiccionales penales interpretaron en un principio estos tipos delictivos de una manera muy restrictiva, pronunciándose muy escasas sentencias firmes condenatorias por delitos contra la ordenación del territorio.

54 Sentencia del Tribunal Supremo ( $S^{\mathrm{a}} 2^{\mathrm{a}}$ ) de 6 de abril de 2009 (casación 1337/2008).

55 Sentencia de 28 de marzo de 2006 —casación 2067/2004-. 
No obstante, se puede apreciar una evolución jurisprudencial hacia el signo contrario, incrementándose gradualmente los procesos incoados y las sentencias de condena ${ }^{56}$. La que ahora comentamos constituye buena muestra de esta reciente tendencia, en la que se refleja la preocupación del órgano juzgador por el grave deterioro del medio ambiente, del paisaje y de la calidad urbana que se está produciendo en nuestro país como consecuencia de las numerosas y graves irregularidades urbanísticas cometidas en connivencia con las autoridades o funcionarios a los que les correspondería perseguirlas.

Esa preocupación no es exclusiva de los órganos jurisdiccionales penales, sino también del propio legislador estatal, que ha decidido incluir la reforma de la regulación de estos delitos en el proyecto de Ley Orgánica de modificación global del Código Penal que en estos momento se tramita en Las Cortes $^{57}$. Pretende con ello endurecer las penas en correspondencia con la gravedad de esta clase de conductas, tipificar otras nuevas (ad. ex. las obras ilegales o clandestinas de urbanización, o en el delito de prevaricación acciones de omisión como la ocultación de actos ilicitos observados por la inspección o la preterición de inspecciones que tuvieran carácter obligatorio), así como establecer medidas accesorias que impidan al delincuente urbanístico obtener beneficio económico alguno por su actuación (por medio de multas, e incluso del "comiso de las ganancias" obtenidas).

Ahora bien, sin perjuicio del efecto de "prevención general" que sin duda estas medidas van a potenciar, resulta sin embargo dudoso que por la vía del endurecimiento de las penas se alcance con mayor agilidad que por el mecanismo administrativo y contencioso-administrativo el resultado que se pretende alcanzar respecto del bien jurídico protegido. Fin último que es la efectiva restauración física de los terrenos sobre los que se ha cometido la infracción urbanística, devolviéndolos a su situación original.

Entiendo que, en puridad, ese objetivo se puede lograr de manera quizás más eficaz por la vía contencioso-administrativa mediante la simple adopción de técnicas tan simples como, entre otras, las siguientes:

- Implantación generalizada de medidas cautelares, como la suspensión de la ejecución de las actuaciones urbanísticas impugnadas, así como de las obras iniciadas a su amparo, impidiendo la consolidación física de la infracción; la anotación preventiva en el registro de la propiedad, etc.

- Ejecución provisional de las sentencias carentes de firmeza que en primera instancia hayan anulado dichas actuaciones.

56 Ad. ex, sentencias del Tribunal Supremo ( $S^{a} 2^{a}$ ) de 25 de noviembre de 2009 (casación 417/2009), 6 de abril de 2009 (casación 1337/2008) y 16 de diciembre de 2009 (casación $1344 / 2009)$.

57 “Proyecto de Ley Orgánica por la que se modifica la Ley Orgánica 10/1995, de 23 de noviembre, del Código Penal", publicado en el Boletín Oficial del Congreso de los Diputados núm. 52-1, de 27 de noviembre de 2009. 
- Adopción en el incidente de ejecución forzosa de las sentencias condenatorias de derribo de las técnicas propias de la jurisdicción civil, como las de "sustitución" por el propio órgano juzgador ${ }^{58}$, etc.

Y en la vía propiamente administrativa, mediante el ejercicio efectivo de las potestades preventivas y coercitivas a las que aludimos en el epígrafe 2 anterior. Una iniciativa que en este sentido está resultando muy eficaz en algunas comunidades autónomas es la asunción, por la propia Administración autonómica, sustituyendo a los ayuntamientos, de la potestad para tramitar y resolver los expedientes de infracción urbanística en los supuestos más graves (construcciones en suelo no urbanizable, por ejemplo).

\section{LA SENTENCIA DEL TRIBUNAL SUPREMO DE 27 DE NOVIEMBRE DE 2009}

En la sentencia del Tribunal Supremo que constituye el objeto de este comentario se refleja, de manera explícita o implícita, lo considerado en los epígrafes anteriores.

Los concretos hechos delictivos que originaron el proceso penal en el que se dictó no son, por desgracia, excepcionales, ni infrecuentes en la práctica urbanística local: un individuo adquiere a bajo precio ${ }^{59}$ una finca clasificada como suelo rústico (no urbanizable) de especial protección paisajística, en la que no se permite la construcción de edificaciones para uso residencial. Esa persona, prevaliéndose de sus vínculos con la Corporación Municipal ${ }^{60}$, solicita en el Ayuntamiento licencia para "ampliación de almacén agrícola", con la intención fraudulenta de realizar en realidad en el referido predio una vivienda unifamiliar desvinculada de cualquier uso agrícola. Los técnicos municipales informan favorablemente la petición en términos laxos y poco rigurosos. Tras el otorgamiento de la licencia se erige en efecto una vivienda unifamiliar tipo "chalet", con porches y taludes para nivelación del terreno y con la consiguiente alteración del paisaje. Como se interponen varias denuncias contra la obra, el Ayuntamiento se ve obligado a tramitar un expediente de disciplina urbanística, que no llega a concluirse y en el que se van sumando irregularidades (actas de inspección que no reflejan la realidad de los hechos, sustracción de documentos, etc). Como guinda final, el promotor de la obra ilegal, que es el propio Alcalde, ordena en represalia por las denuncias la incoación de procedimientos sancionadores contra regidores de la

58 BELTRÁN DE FELIPE, M. «El poder de sustitución en la ejecución de las sentencias condenatorias de la Administración”. Cívitas, Madrid, 1995. GEIS I CARRERAS, G. “La ejecución..... op. cit., págs. 295 y ss.

59 Por 30.000 euros, en el año 2002, un terreno de unos $4.000 \mathrm{~m} 2$ de superficie, en el término municipal de Andraitx (Palma de Mallorca).

60 Se trata del propio Alcalde-Presidente del Ayuntamiento. 
oposición municipal y algunos de sus familiares, aún a sabiendas de que las hipotéticas infracciones que les pretende imputar habrían prescrito en cualquier caso tiempo atrás.

En el año 2008 la Audiencia Provincial de Palma de Mallorca dictó sentencia en la que condenó al promotor y dueño de la obra a un total de cuatro años de prisión, más inhabilitación y multa, como inductor de un delito de prevaricación administrativa y como autor directo de un delito contra la ordenación del territorio. También condenó a penas de prisión e inhabilitación al que, cuando acaecieron los hechos, ejercía de jefe de urbanismo del Ayuntamiento ${ }^{61}$, así como al asesor jurídico que informó el expediente de la licencia y al inspector que lo hizo en el sancionador, por delitos contra la ordenación del territorio y prevaricación. Por último ordenó el derribo de la vivienda a costa del infractor.

La sentencia del Tribunal Supremo que comentamos confirmó en casación la de la Audiencia Provincial, tras resolver, entre otras las siguientes cuestiones controvertidas:

\section{A) ANTIJURICIDAD MATERIAL DE LOS HECHOS INFRACTORES EN RELACIÓN CON EL PRINCIPIO DE MÍNIMA INTERVENCIÓN PENAL}

Esgrimió el promotor recurrente que, en el peor de los casos, los hechos denunciados podrían ser constitutivos de una infracción administrativa, pero no penal, al afectar escasamente al bien jurídico protegido. De una parte, porque la calificación urbanística de la parcela permitiría ejecutar en ella una construcción de uso agrícola con volumen y altura similar a los de la realizada. Y, de otra, porque se sitúa en un lugar, próximo al núcleo urbano de Andratx, en el que ya existen edificaciones de muy escaso valor estético.

El Tribunal Supremo responde a dichas objeciones con rotundidad y claridad, poniendo de manifiesto los valores constitucionales a los que antes aludimos, así como su grave lesión por prácticas urbanísticas ilícitas como la enjuiciada, frente a las que el Derecho administrativo ofrece escasos resultados.

Y así reconoce, en primer lugar, que: "la desastrosa situación a que, a pesar de la normativa legal y administrativa, se ha llegado en España respecto a la ordenación del territorio, incluida la destrucción paisajística, justifica que, ante la inoperancia de la disciplina urbanistica, se acuda al Derecho Penal, como Última Ration.

En segundo lugar, que en esta materia el ilícito urbanístico afecta de manera significativa a "intereses colectivos difusos", ya que "No cabe ignorar que la comunidad de ciudadanos es víctima de los despropósitos urbanisticos y que la Administración urbanistica también experimenta las consecuencias de las infracciones en materia de ordenación del territorion.

61 Función que mantuvo "de hecho", según la sentencia, tras su posterior nombramiento como Director General de Ordenación del Territorio del Gobierno de las Islas Baleares. 
Y en tercer y último lugar, que en este concreto caso "la profunda lesión del bien jurídico protegido trae causa en buena parte del efecto acumulativo provocado por las transgresiones". Incidiendo, en lo que a la protección del paisaje se refiere, en que "la perspectiva es elemento esencial; el desconocer la importancia de tal elemento ha llevado a la situación desastrosa de algunas partes de España en orden a la ordenación del territorio".

A todo ello podría añadírsele la especial repugnancia y el rechazo social que produce en la comisión del acto ilícito la condición de Alcalde-Presidente de su principal autor. En su calidad de representante ordinario del Ayuntamiento debía velar de una manera especial por el cumplimiento de la legalidad urbanística, prodigándolo con su propio ejemplo. Por el contrario, prevaliéndose de su cargo público y en connivencia con sus subordinados servidores públicos también-, se procuró su beneficio personal adquiriendo una finca a precio de inedificable para destinarla luego a un uso residencial prohibido, lesionando los valores constitucionales ínsitos a su clasificación como suelo no urbanizable, en perjuicio de sus propios conciudadanos, los cuales además, al verse obligados a dar cumplimiento al ordenamiento urbanístico, habrían de padecer un trato desigual, con el consiguiente agravio comparativo.

Otro tanto podría decirse sobre su principal cómplice, en quien al inicio de los hechos concurría la condición de jefe de urbanismo del Ayuntamiento y durante su posterior discurrir la de Director General de Ordenación del Territorio del Gobierno Balear.

\section{B) Concurso ideal de Delitos}

Se esgrimió también en el recurso de casación un quebrantamiento del principio de "non bis in idem", al habérseles imputado, en razón de unos mismos hechos, la comisión de dos delitos que son excluyentes entre sí. Y ello porque, a su entender, el delito contra la ordenación del territorio (art. 319.1 $\mathrm{CP}$ ) es de resultado, suponiendo una mera intensificación del injusto de la prevaricación urbanística (art. $320 \mathrm{CP}$ ), al progresar por el iter criminis de aquél.

El Tribunal Supremo rechaza esta argumentación tras considerar que los bienes jurídicos protegidos por ambos tipos delictivos no son estrictamente coincidentes, dado que "el bien tutelado con la sanción penal a la prevaricación urbanística no es sólo la ordenación del territorio, sino también la Administración pública, como en toda prevaricación administrativa".

\section{C) Elemento Subjetivo Del injusto.}

En la práctica, como se ha dicho, la mayor dificultad que se plantea en esta clase de procesos reside, por lo general, en la constatación del elemento 
subjetivo del tipo delictivo, es decir, en la necesidad de demostrar de manera indubitada el dolo, la intencionalidad maliciosa de su autor. Éste, sobre todo en los supuestos de prevaricación, se apoyará en algún resquicio de la prolija, compleja y en ocasiones contradictoria normativa urbanística para darle a su conducta un mínimo soporte legal suficiente para enervar su responsabilidad penal.

En el caso examinado sin embargo el Tribunal Supremo consideró suficientemente probada la intencionalidad de los acusados en la producción de un resultado injusto, sin que actuaran «bajo error determinado por una equivocada interpretación de preceptos", considerándose la estrecha relación que mantenían entre ellos, así como su conocimiento técnico sobre la materia. Y, a mayores, con la circunstancia agravante, en lo que se refiere al promotor de la obra ilegal, de prevalerse, para perpetrar el delito, de su condición de miembro de la Corporación municipal.

*** *

TrTLE: Criminal offence in urban plannings: criminal protection of basic contitutional principles. Comment on $27^{\text {th }}$ November 2009 judgment of the Supreme Court.

ABSTRACT: The judgment mentioned confirmed a prison sentence, disqualification and a fine imposed to several authorities and public servers for crimes against the urban planning law as well as town-planning corruption, related to the illegal construction of a house in a non-urban and protected area on Mallorca island. The author insists on the constitutional relevance of the affected values by the infraction committed, linked to the rights of all citizens to enjoy a good quality of life in a adequate environment in which the landscape plays a major role. Despite the fact that the administrative law offers numerous measures against this kind of aggressions, the magnitude and the frequency of the latter convey an image of failure that criminal law tries to reduce by regulating the most serious infractions as offence and punishing them with severe sentences.

RESUMEN: La sentencia comentada confirmó la condena de prisión, inhabilitación y multa impuesta a varias autoridades y servidores públicos por la comisión de delitos contra la ordenación del territorio y prevaricación urbanistica relacionados con la construcción ilegal de una vivienda en suelo no urbanizable protegido en la isla de Mallorca. El autor ahonda en la relevancia constitucional de los valores afectados por la infracción urbanistica cometida, vinculados al derecho de todos los ciudadanos a disfrutar de "calidad de vida", en un medio ambiente adecuado en el que el paisaje es un elemento fundamental. Aunque el Derecho administrativo ofrece numerosas medidas preventivas y coercitivas frente a este tipo de agresiones, la magnitud de las mismas y su frecuencia transmiten una imagen de fracaso que el Derecho penal pretende paliar tipificando como delito las infracciones más graves y sancionándolas con severas penas. life.

KEY wORDS: Planning breach. Failure of administrative law. Right to enjoy a good quality of

Palabras clave: Delito urbanístico. Derecho a disfrutar de una calidad de vida. Fracaso del Derecho administrativo. 